\title{
Research on Professional Emotional Cultivation of Computer Major Based on School-Enterprise Cooperation
}

\author{
Xiujuan Sun \\ Information Science and Technology, Taishan University \\ Taian, China
}

\begin{abstract}
Traditional computer teaching pays less attention to professional emotional cultivation than education of knowledge and skills, which leads students to have lower interest in learning, resulting in poor teaching effect. In fact, professional emotions will improve students' learning interest, drive students to actively internalize knowledge and skills, and build their own knowledge system. By professional emotional training, students will have stronger ability to transform knowledge into productive forces. But on the question of professional emotional cultivation, the effort which schools can make is single and limited. Because enterprises have always been in the forefront of industry, they have unique advantages in professional emotional cultivation. Under the mode of school-enterprise cooperation, schools and enterprises should jointly conduct professional emotional cultivation, so that students can gain stable and powerful strength to improve their autonomous learning ability and professional tendency, and promote the individual sustainable development in the professional field.
\end{abstract}

Keyword —Professional emotional cultivation; Computer major; School-enterprise cooperation; Sustainable development

\section{INTRODUCTION}

Computer science is a subject combining theory with practice, and its application value has extended in many fields of production and life. The social requirements for computer major are also increasing with quantity year by year. However, computer major have exposed many problems in employment. Some students are at a loss about the development of the industry, some students' professional skills don't reach the standard, and some students are not interested in their industry and change their careers. The reason is that the professional emotional cultivation of computer major didn't fall to the ground, so that students lacked of professional identity, professional pride, professional achievement and professional belonging.

\section{The CONNOTAtion OF Professional EMOTION}

Professional emotion refers to the individual inner experience whether his major can satisfy both his own psychology and social need. Lenin, the revolutionary teacher, said, "Without emotion, human can't pursue the truth forever." Once the professional emotion is formed, it will produce a stable and powerful force which will positively affect and adjust students' interest in learning [1]. All teaching have feelings, no feelings of the teaching and learning are short, no matter how much knowledge, or repeated memory of how many times, if there is no emotional investment, these will vanish with time [2]

The cultivation of computer professional emotion aims to improve students' interest in learning and transform the interest into stable professional emotion through various ways. Professional emotions will drive students to actively internalize knowledge and skills, and build their own knowledge system. By professional emotional training, students will have the ability to transform knowledge into productive forces. At the same time, the emotion of computer science is an important part of computer science culture, also a driving force to promote the development of computer science [3]. Therefore, while imparting knowledge and skills, we should spare no effort to cultivate professional emotion.

Professional teachers have teaching tasks and work on the teaching frontline over the years. The effort that they can make to cultivate professional emotion is single and limited. Under the school-enterprise cooperation model, enterprises can assist schools to carry out professional emotional cultivation.

\section{SCHOOLS ASPECT}

Professional emotional cultivation must run through the whole teaching process. Its implementation should adhere to the people-oriented principle, and play the leading role of teachers and the dominant position of students. The school can carry out professional emotional training through the following ways.

\section{A. Designing a comprehensive teaching content}

Students' basic level and learning initiative are uneven. If the teaching content just considers cognitive level, students' interest is low, and learning effect is poor. Therefore, the talent training program, the curriculum outline and the goal of lesson hours all should be designed and arranged from knowledge, skills and emotion dimensions [4]. Schools should strive to take emotional cultivation into account from top-level design to teaching implementation. Both cognition and emotion are equally important. Besides, the teaching content should be linked to the teaching objects, and take the students' basic situation into account. 


\section{B. Establishing a symphonious teacher-student relationship}

In order to achieve good result, teaching needs a harmonious soft environment. A symphonious teacher-student relationship can stimulate students' enthusiasm and initiative in learning, and promote the realization of teaching objectives. Contemporary college students have the characteristics of active thinking and distinct personality. First of all, teachers should fully respect and value students' individuality, and think over their aptitude in the teaching process. The comprehensive quality of teachers is an important factor in the formation of students' professional emotions. Teachers should constantly improve the teaching level and the appeal of curriculum teaching [5]. Teaching is serious and rigorous, but we can try our best to complete teaching activities in a loose and active form. In addition, teachers and students can also communicate and feedback through seminars, teaching evaluation, various online platforms to improve the teaching modes and teaching methods.

\section{Setting up a favorable teaching situation}

There are kinds of teaching situations, such as problem situation, experiment situation, activity situation, etc. [6] A favorable emotional teaching situation has the function of guiding students to think and experience the experimental world, then furtherly promotes the formation and internalization of professional emotion. Therefore, teachers should be good at creating different teaching situations in teaching activities. Among them, the problem situation is used commonly. Heuristic teaching is adopted to improve students' abilities of finding and solving problems. Teacher can even deliberately set traps in the teaching, so that students can experience failures and deepen their understanding and impression of knowledge from failure cases. Taking the data input in Excel as an example. Teacher firstly inputs the regular text data and numerical data in the way of "input is output" in the Word document, which one is familiar to students. The students think the result is beyond doubt. Then the teacher enters the more usual information in life, such as the student number and identity card number. At the time, students will find the result is not in line with expectation. Their psychology will have contrast and confusion, which conversely arouse students' interest in learning. Researches show that teaching effect is remarkable if teaching and learning with the concrete problem.

\section{Adopting reasonable case teaching}

Case teaching is a common teaching mode in computer teaching. Case teaching should follow some design principles, for example, from easy to difficult, from single to comprehensive. These principles can ensure that students are easier to receptive, practical and internalize. The selection of cases should consider the following aspects.

- For the purpose of professional emotional cultivation, the cases should reflect professional superiority, so that students can feel professional pride and accomplishment. For example, when learning the Word software, students can use the "merge mail" function of the Word to produce admission notices in large quantities. Students can intuitively feel the convenience brought by computer science, and their interest in learning will be increased.

- Cases should be close to students' daily life, so that students can more easily understand and find out the application value of computer science. For example, using an average case to explain the average function and "auto-fill" function in Excel. The average function is used to calculate the average score of the first student, and then "auto-fill" function is used to calculate the average scores of other students. Changing a certain data, Excel can automatically update the operation result. In this case, students can feel the convenience and surprise brought by the computer science.

- Cases should be inspiring and representative, which can improve students' abilities of logical thinking and analogy.

- Difficulty of cases should be moderate. It is best to solve the problem through the combination of new knowledge and the existing knowledge of students, which can help students to experience the links between knowledge and build up their confidence in learning. For example, teacher leads students to rank a grade table containing hundreds of records in Excel. Teacher let students to think about how to solve it. Students may use scores to sort according to their knowledge and experience. Then, the request of modifying certain records is put forward. After modification, it is necessary to reorder the data based on the new records. Students will immersive feel that the method is troublesome. At this time, the teacher proposes that rank function can rank quickly and Excel can automatically re-rank according to new records. Comprising different methods can deepen the understanding of knowledge points. More importantly, students can widely use, practice and internalize the knowledge point in future study.

\section{E. Constructing practical teaching environment}

The practical environments are divided into two types: real one and virtual one. Schools should bring students into actual job posts to experience industry as much as possible. School can also introduce the enterprise into the school for professional training. These practices can improve students' professional emotion through perceptual recognition. Practice, as an extension of knowledge, requires students to use hands and brains at the same time. Practice can enhance students' sense of professional pride, achievement and satisfaction. After the employment, employees often form teams to develop projects. The job will test employees' team consciousness and cooperation abilities. Therefore, driving by innovational and enterprising projects, interest groups can be set up to cultivate students' team cooperation ability. Through the training, students can adapt to the employment soft environment in advance. 


\section{ENTERPRISES ASPECT}

Enterprises have always been in the forefront of industry, have access to the latest information and technology, have a forward-looking judgment on the development of the industry, and know the professional qualities needed by practitioners. Therefore, enterprises have unique advantages in professional emotional cultivation. The specific work can be carried out from the following aspects.

\section{A. Professional guidance}

The professional guidance lecture is arranged before the professional lecture. Enterprises send professional tutors to the school to give students a general introduction on the major and the industry, so that students can have a sense of the computer science and build professional emotion ahead of time. The professional emotion is initially formed to facilitate the development of professional courses. There are five questions will be answered in this course. (1) What can computer does? Professional tutors can answer the question by exampling. Examples should be closely related to students' life. These examples can shorten the distance between the computer major and students and make students feel that the world belong to computer science. The lecture also introduces the hot fields and high technologies of computer science. Then students will feel that the world depends on computer, and have professional pride and higher aspirations. (2)Which jobs can students choose and what are their employment prospects? Through studying the course, students will have clear objectives. (3) Which professional knowledge and skills do students need to prepare in order to achieve employment? Take the computer products which students are interested in as an example, such as a certain APP, to analyze the products from the function to software and hardware. Tutors should use plain language in the process. Students will know which professional knowledge is used, which courses are related to, and when they can begin to practice a similar small project. Students will have practical learning goals and motivating force in the course. (4)Which professional qualities do students need to cultivate? From the aspects of operation norms, laws and regulations, team cooperation, professional ethics, etc., students will understand some norms which they have to abide by. From now on, they should deliberately cultivate their own professional qualities. Five, which ways can improve their professional quality? In this respect, some cases of successful men can be introduced to reveal the efforts behind the success. The professional guidance course is set up before the professional course. The professional tutors should use plain examples to assist the course, so that students can have an intuitive feeling about the major and the industry. The examples will also arouse students' interest and yearning for the profession.

\section{B. Semester coaching}

Professional teachers should introduce the course objectives before the beginning of course. Professional tutors are responsible for sorting out the structure of the curriculum system and helping students understand the internal relationship among the curriculums. Especially through one semester's study, students should clear specific projects which they can complete and courses which support these projects with the help of tutors. By understanding above questions, students will have goals, passion and expectations for learning. In order to ensure the effect, professional tutors are required to often enter the campus to find and solve problems at any time, and continuously cultivate professional emotions in the teaching process. When introducing some advanced information and technology, professional tutors are responsible for delivering experience, lessons, reference materials and practical approaches to students to guarantee their cognitive education and emotional cultivation.

\section{Project-driven professional qualities training}

Computer science is a science combining theory and practice. All knowledge and skills will be eventually embodied in the form of achievements. This especially adapt to employment. Under the mode of school-enterprise cooperation, computer majors mostly introduce personnel and projects from enterprises to carry out practical training for students, in order to improve students' practical abilities and enhance their employment competitiveness. Besides, students should understand that a good social environment can guarantee the better development of major and individuals. The students trained by school-enterprise cooperation should not only realize employment, but also have social responsibilities. They will combine personal interests with social interests, and realize the sustainable development of major and individual.

In addition, professional emotional cultivation can also be carried out in more flexible ways, for example comprehensive quality courses.

\section{CONCLUSION}

In addition to imparting knowledge and skills, computer majors should also pay attention to the professional emotional cultivation. The purpose of professional emotional cultivation is to improve students' professional awareness and professional interest, strengthen their abilities to think independently and study deeply, maintain a lasting enthusiasm for occupation, and promote their own sustainable development in the professional field. Under the school-enterprise cooperation model, professional emotional cultivation needs schools and enterprises to exploit their respective advantages, and cooperate to provide students with a more comprehensive and three-dimensional educational environment. Schools and enterprises create as many opportunities as possible for students to contact with professional technology, working environment and professional frontier, provide continuous technical support and professional emotional cultivation, and ensure that students have been in professional atmosphere. 


\section{REFERENCES}

[1] Beibei Jin, Research on the meaning and method of higher vocational students' professional emotional cultivation", in SHANGYE JINGJI, no.9, 2007, pp. 114-115. (In Chinese)

[2] Li Nian, Fei Wang, "On the importance of emotional cultivation in vocal music teaching", in International Journal of Technology Management, no.6, 2017, pp. 13-15.

[3] Yan Wang, Jian Guo, "Research on teaching mode of discrete mathematics based on emotional training of computer subject", in Computer Education, no.3, 2016, pp.19-21. (In Chinese)

[4] Xinqiong Zhang, "The training of students occupational emotion in specialized com-se teaching", in Nursing Practice and Research, no.2, vol.3, 2006, pp.63-64. (In Chinese)

[5] Lin liu, Ying Liu, "Application of Emotion in the Computer Teaching of Universities", in computer programming skills and maintenance,2014, pp.136-137. (In Chinese)

[6] CuiYing Su, "The Implementation Strategy of Emotional Teaching Goal in the Teaching of Computer Specialized Courses, in China Education Innovation Herald,no.29, pp.192. (In Chinese) 